\title{
The impact of electricity storage on wholesale electricity prices
}

\author{
Batsaikhan Nyamdash ${ }^{\mathrm{a}, *}$, Eleanor Denny ${ }^{\mathrm{a}}$ \\ ${ }^{a}$ Department of Economics, Trinity College Dublin, Ireland
}

\begin{abstract}
This paper analyzes the impact of electricity storage on the production cost of a power system and the marginal cost of electricity (electricity price) using a unit commitment model. Also real world data has been analyzed to verify the effect of storage operation on the electricity price using econometric techniques. The unit commitment model found that the deployment of a storage system reduces the fuel cost of the power system but increases the average electricity price through its effect on the power system operation. However, the reduction in the production cost was found to be less than the increase in the consumer's cost of electricity resulting in a net increase in costs due to storage. Different storage and $\mathrm{CO}_{2}$ price scenarios were investigated to study the sensitivity of these results. The regression analysis supports the unit commitment results and finds that the presence of storage increases average wholesale electricity prices for the case study system.
\end{abstract}

Keywords: Electricity storage, Electricity price, Production cost

\section{Introduction}

The European Union has committed to reducing greenhouse gas emissions by increasing the share of renewable energy in the energy mix and increasing energy efficiency by 2020 (European Commission, 2006, 2007). In meeting these commitments, wind energy has attracted more attention than other renewable energy sources (RES) (i.e. tidal, wave, geothermal etc.) as it is currently considered to be the most economical renewable generation type.

As the role of RES increases in the power system, changes to the power system operation are required such as greater reserve capacity from conventional power plants to deal with unanticipated reductions in renewable energy generation (Doherty et al., 2005; Dany, 2001). In order to accommodate the variability and uncertainty of wind generation, thermal generators are often required to operate on a sub-optimal regime which can impose additional cycling on these units (Denny and O'Malley, 2007). Moreover, it requires increased network enforcement due to the wide and remote geographic dispersion of wind farms.

*Corresponding author can be contacted at batsaikn@tcd.ie, tel: +35318962325. 
Therefore, the use of electricity storage systems, which store electric energy in terms of water in elevated reservoirs or compressed air in underground caverns etc., are attracting more attention in a bid to increase renewable energy penetrations (McDowall, 2006; Weis and Ilinc, 2008). Such systems are able to provide fast startups and rampings, thus allowing the power system to offset the impact of renewable energy generation (Brown and Lopes, 2008; Zeng et al., 2006; Abbey and Joós, 2007; Li and Joós, 2007; Carton and Olabi, 2010). The integration of storage in weak networks with an intermittent energy source improves power quality and reduces the cost of electricity significantly (Kaldellis et al., 2009). Korpaas et al. (2003a); Benitez et al. (2008) found that the deployment of storage reduces the need for generating capacity. Also, it may decrease the wind curtailment and shift off-peak wind power output to the peak hours. However, large scale storage units are site specific and capital intensive (Susan and Hassenzahl, 2003; EPRI, Palo Alto, 2003; EPRI, 2004).

It has been shown that optimally sized electricity storage could result in more economic operation of both wind farms and the storage itself by taking advantage of arbitrage, ancillary services, and transmission and balancing costs (Korpaas et al., 2003b; Castronuovo and Lopes, 2004; Leou, 2008; Greenblatt et al., 2007; Lund et al., 2009; Kaldellis et al., 2009; Zafirakis and Kaldellis, 2009; Sioshansi, 2011; Tuohy and O‘Malley, 2011). In addition, the distributed storage system has the potential to reduce the electricity cost of the household (Ahlert and Block, 2010). The hydrogen storage concept has been studied from an investment perspective and it was found that the use of hydrogen storage for electricity generation is uneconomical (Taljan et al., 2008). Nyamdash and Denny (2010) found that electricity storage is not viable if it is considered only from the perspective of the developer for 2007 Irish power system since the peak and off-peak price differentials are insufficient to cover round-trip efficiency losses. Storage benefits depend on the location of the storage, whether it is close to the transmission line or the utility and also the type of the system (Nieuwenhout et al., 2005). Sioshansi (2010) shows that storage utilization depends on whether it is operated by the individual power plant, consumer or operated as a standalone unit. Troy et al. (2010) looked at the large scale storage benefits from the power system perspective.

From the perspective of the power system, storage benefits would be significant when failure occurs in the power system. However, most of the storage benefits, such as reduction of the variability of renewable generation, deferring of transmission and distribution investments, and capacity investments are case-specific. Benefits relating to the supply of ancillary services are also market specific.

One way of looking at the storage system from the perspective of society, which has 
received relatively little attention, is to estimate the effect of storage on the electricity price. In a purely theoretical framework, the operation of storage is able to decouple the load from the generation, and reduce the electricity cost for consumers (Crampes and Moreaux, 2010; Sioshansi et al., 2009; Weissensteiner et al., 2011). However, this is challenging to explicitly examine, as the electricity price often consists of various elements and the methodology is not uniform through different markets. But, implicitly if storage can affect the average wholesale price of electricity generated, it is likely to have a similar effect on the end-use electricity price. Since electricity storage uses the electricity produced by power plants, the operation of the storage unit affects the economic dispatch of thermal power plants; hence the wholesale electricity price. Thus, the effect of storage on the power system operation and the electricity price is unlikely to be specific to the storage technology adopted but it will depend on the case system.

This paper looks at large scale electricity storage, which is used to minimize the total cost of the power system, from a societal perspective. This is done by estimating the value of storage in terms of its effect on the wholesale electricity price for the case study system for various storage scenarios as well as estimating its effect on the total production cost of the power system. The WILMAR ${ }^{1}$ (Wind Power Integration in Liberalized Electricity Markets) tool is used to model the unit commitment decisions. The impact of storage operation on the shadow price of electricity of the Irish Single Electricity Market is investigated econometrically.

The rest of the paper is organized as follows. Section 2 reviews the case system, scenarios, the unit commitment model and the econometric model. Section 3 shows the results, Section 4 presents the discussions and Section 5 concludes.

\section{Methodology}

\subsection{Case study system and scenarios examined}

The case study system is based on the 2009 Irish power system and the plant portfolio is adapted in the WILMAR tool to match the 2009 system. The maximum demand was $6467 \mathrm{MW}$ while the minimum demand was $1826 \mathrm{MW}$ in $2009^{2}$. The thermal capacity

\footnotetext{
${ }^{1}$ The WILMAR planning tool is a unit commitment model that is being widely used in power system analysis (National Laboratory for Sustainable Energy, 2010; AIGS, 2008; European Wind Integration Study, 2010; Tuohy et al., 2009b).

${ }^{2}$ SEMO (2011) publishes the system load rather than the demand level. Therefore the proxy for the demand level is estimated by the following expression: Demand $t=$ SystemLoad $_{t}+$ Import $_{t}-$ Export $_{t}-$ StorageCharget. The system load includes the generations of all generating units including renewable generations in the Republic of Ireland and Northern Ireland.
} 
consisted of coal, gas, oil and peat fired power plants. In total, 46 conventional power plants are modeled and they are summarized in Table 1 . The renewable capacity consists of an aggregated hydro unit and an aggregated wind farm in such a way that there is only one combined hydro and one combined wind unit. Renewable electricity generation has a priority dispatch in the Irish system meaning that generations from RES are given precedence when dispatch decisions are made (CER, 2008). The maximum wind power output in 2009 was 1054MW. The largest conventional unit modeled has a maximum power capacity of 480MW (SEMO, 2011). There is one interconnector in the Irish system and its import capacity is assumed to be $400 \mathrm{MW}$ while its export capacity is assumed to be $80 \mathrm{MW}$. A simplified Great Britain power system with aggregated power plants is also assumed when modeling interconnector flows. There is one existing storage system in Ireland which is a pumped hydro system and it is currently utilized to minimize the overall production cost of the power system.

\begin{tabular}{|c|c|c|c|c|c|}
\hline \multirow[t]{2}{*}{ Type } & \multirow{2}{*}{$\begin{array}{l}\text { Number } \\
\text { of units }\end{array}$} & \multirow{2}{*}{$\begin{array}{c}\text { Total } \\
\text { capacity }(\mathrm{MW})\end{array}$} & \multicolumn{3}{|c|}{ Fuel Price } \\
\hline & & & $R o I^{1}$ & $N I^{2}$ & $G B^{3}$ \\
\hline Peat (baseload) & 3 & 343 & 3.71 & & \\
\hline Coal (baseload) & 5 & 1324 & 1.75 & 2.11 & 1.75 \\
\hline Base-load gas & 17 & 4123 & 7.06 & 7.06 & 4.16 \\
\hline Mid-merit gas & 4 & 508 & 7.26 & 7.27 & 6.9 \\
\hline Oil (peaking) & 17 & 1962 & 9.64 & 8.33 & 9.64 \\
\hline Hydro & & 216 & 0 & 0 & 0 \\
\hline Wind & & 1054 & 0 & 0 & 0 \\
\hline
\end{tabular}

The base-case scenario for the analysis is 'no-storage. This scenario assumes 0MW of installed storage capacity. Storage scenarios with 200MW, 400MW, 600MW and 800MW of installed capacities with an energy capacity of 5 hours are compared against the basecase scenario, in all cases replacing the existing pumped hydro system. Storage unit is assumed to be the power system asset; hence the power system operator decides when the storage unit should pump and generate ${ }^{3}$. The plant mix is not assumed to be affected by the addition of the storage unit to the power system (i.e. new storage units do not displace any thermal unit) as the storage unit is energy limited and is not the perfect substitute for conventional power plants (Walawalkar et al., 2007; Tuohy and O'Malley, 2011).

The assumed fuel prices are shown in Table 1. Fuel prices are assumed to remain constant throughout the year. A carbon price of $€ 30 /$ ton was assumed.

\footnotetext{
${ }^{3}$ Thus, electricity price is not taken into account when storage outputs are being scheduled. However, if the storage unit is operated as merchant type, which it buys electricity from the market place and sell back, the selling price of the electricity should at least be $1 /$ (efficiency of the storage unit).
} 


\subsection{Unit commitment model}

The WILMAR Planning Tool, which is a dynamic partial equilibrium model of the electricity sector, finds the economic dispatch of generating units over the optimization period based on the demand and wind forecasts. It takes into account power plant constraints, such as minimum downtime (the minimum time a unit must remain offline following shutdown), synchronization times (time taken to come online), minimum operating time (the minimum time a unit must spend online once synchronized), heat rate (efficiency of the generator) and ramp rates. The model has an hourly resolution, with planning being done for the next 36 hours on a rolling basis. The deterministic version of this tool, which assumes the perfect wind forecast, was used in this paper. Definition of the objective function and further details are given by Tuohy et al. (2009a); Troy et al. (2010). The electricity price is determined by the marginal cost of an extra one MWh of electricity produced by the power system.

Storage is assumed to provide reserves (primary and secondary) to the power system. In the model, the storage unit is represented by a reservoir, with the inefficiencies associated with pumping and generating accounted for when filling the reservoir. The round-trip efficiency assumed (KWh produced divided by KWh stored) is $75 \%$. When pumping, electricity used to pump is added to the system demand, and the amount being pumped is subtracted from primary and replacement reserve targets, as pumping can be stopped to reduce demand on the system. When generating, it is treated as any conventional unit. Both pumping and generating are subject to ramping and minimum and maximum capacity constraints, as any other unit. However, a pumped storage unit usually has a very high ramping rate, which when examined on an hourly resolution means that storage can go from full pumping capacity to full generating capacity in less than 1 hour. All units are assumed to serve one reservoir in order to avoid a situation where generation and pumping occurs at the same time for different units ${ }^{4}$. To ensure there is energy in the storage system at the end of the day, the minimum storage content level is accounted for.

Here we assume that the storage system is pumped hydro, however the same approach could be used to assess other types of storage units, such as battery, by simply using different round-trip efficiencies. No scheduled and forced outages are considered for generating units.

The Generic Algebraic Modeling System (GAMS) was used to solve the unit commitment problem using the mixed integer feature of the Cplex solver. For all the simulations

\footnotetext{
${ }^{4}$ This constraint is used as the most common setup for the pumped hydro electricity storage with a reversible turbine/generator.
} 
in this study, the model is run with a duality gap of $0.01 \%$.

While the WILMAR tool is not a perfect model of the actual market design (gross pool) of Ireland's electricity system, it is an appropriate proxy for the dispatch decisions within the marketplace.

\subsection{Econometric estimations}

End-use electricity prices do not tend to respond to power system shocks in the short run because end-use prices are usually based on the long run marginal cost of electricity production. However, wholesale prices would respond to any structural changes in the power system, which would in time feed into end-user prices (Friedman, 2009). Thus, examining the effect of storage on the wholesale electricity price would show the value of storage from the societal perspective.

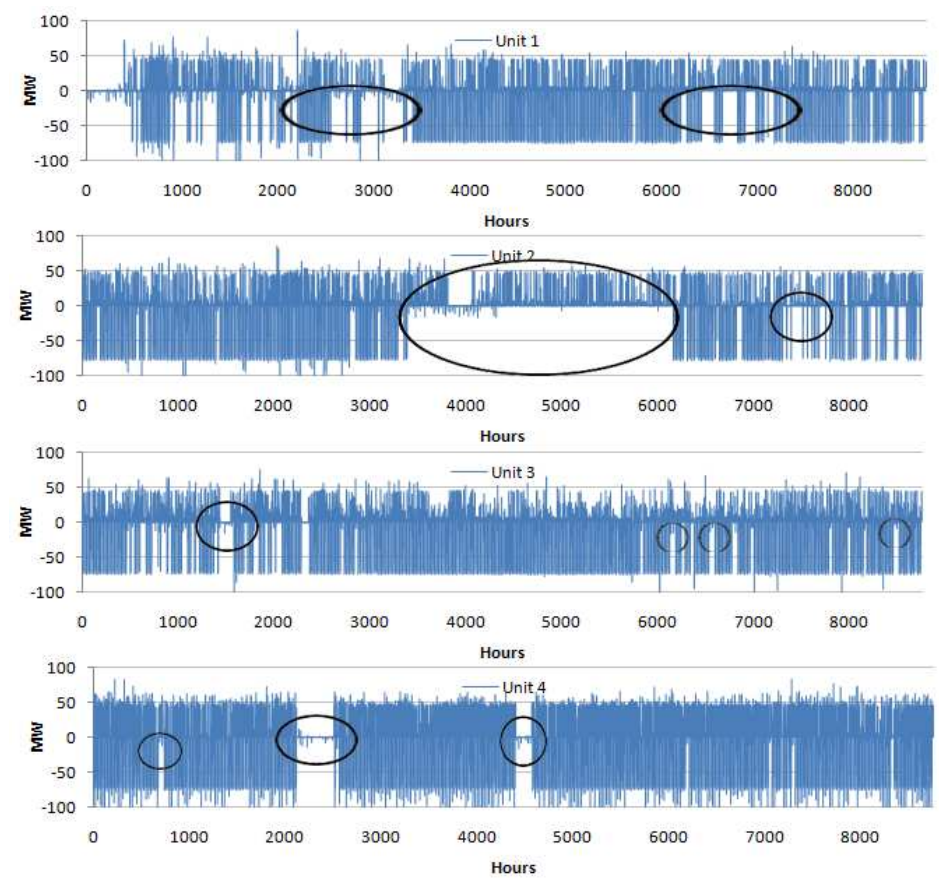

Figure 1: Hourly generation profiles of Turlough Hill pumped hydro storage units.

In an attempt to explore the impact of storage on the wholesale electricity price econometrically, the actual storage output level for the year 2009 was investigated. Since storage output levels are scheduled based on the demand level, RES generation and power 
system operation, it was not possible to include it in the regression as an explanatory variable as it would result in perfect multicollinearity. Therefore, a proxy for storage operation that is not correlated with demand and wind level is required. The pumped hydro storage units in the Irish system were subject to number of scheduled outages in 2009 (EirGrid, 2009b,a,c,d). Figure 1 shows the actual storage generation profile for each unit of storage system. It shows that the storage units were subject to a number of scheduled ${ }^{5}$ and unscheduled outages (examples are marked by circles). The dispatch order of the conventional plants will be different when storage is available and the wholesale electricity price will thus change depending on storage availability when everything else is held constant i.e. demand level, wind speed, fuel and carbon prices.

The following regression model is estimated to examine the effect of storage interruption on the shadow price of electricity:

$$
S M P_{t}=\alpha+\beta_{1} D_{t}^{\text {pump }}+\beta_{2} D_{t}^{\text {generation }}+\gamma_{1} X_{t}+\gamma_{2} X_{t}^{2}+\gamma_{3} P_{t-24}^{e}+\omega_{t}+e_{t}
$$

where $D_{t}^{\text {pump }}$ is a dummy for a interruption in storage pumping, $D_{t}^{\text {generation }}$ is a dummy for a interruption in storage generation, $X_{t}=\left(\right.$ Demand $_{t}$, Wind $\left.t\right)$ are demand and wind profiles, $P_{t}^{e}=\left(P_{t}^{\text {oil }}, P_{t}^{\text {gas }}, P_{t}^{\text {coal }}, P_{t}^{\text {carbon }}\right)$ is oil, gas, coal and carbon prices, $\omega_{t}$ is the unobserved heterogeneity, and $e_{t}$ is the error term.

\section{Results}

\subsection{WILMAR results: Storage operation}

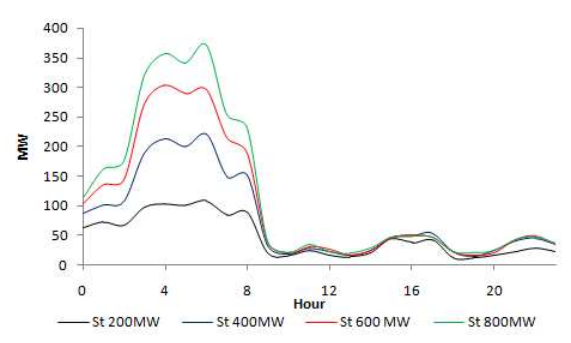

Figure 2: Hourly average charge profile of storage units.

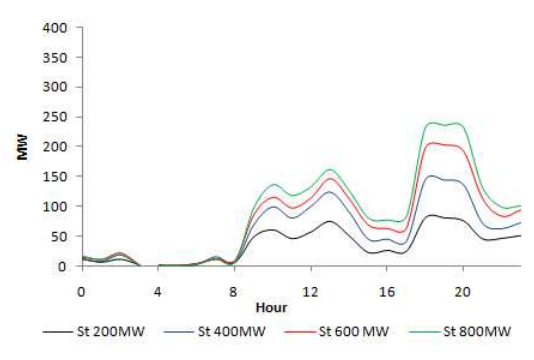

Figure 3: Hourly average generation profile of storage units.

Figure 2 shows the hourly average storage pumping profiles for different levels of storage capacity. It is shown that the storage was used to pump the water using surplus

\footnotetext{
${ }^{5}$ Power plants are periodically taken off the power system for several days to several weeks for the maintenance.
} 
electricity of the power system throughout the night and day. The utilization rate was found to be considerably higher during the night than during the day. It was also found to increase as the available storage capacity increases while the utilization rate during the day does not change. This demonstrates that the storage is charged mostly by the off-peak generations of conventional power plants.

In terms of the storage hourly average generation profiles (Figure 3), it was found that storage would only generate during the day and the total amount of generation was found to increase as the storage capacity increased.

\subsection{Simulation results: Effect of storage on power system operation}

If the dispatch decisions relating to the conventional power plants change depending on the availability of the storage capacity, the wholesale price set by those plants would be different depending on the availability of the storage unit. Therefore, the generation output from those plants during the night and during the day need to be looked at separately.

Theoretically, the deployment of storage should increase the generations of conventional power plants at night and decrease during the day. Although, when technical constraints of the power system are taken into account, the effect of storage may not be as expected.

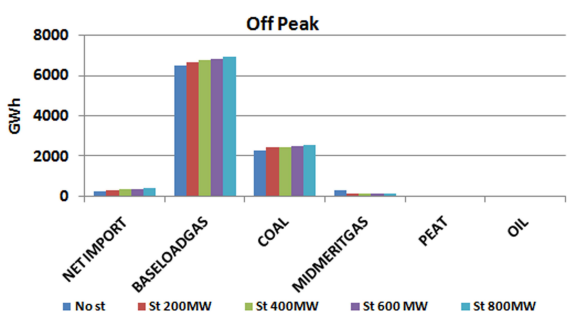

(a) Total annual generation outputs

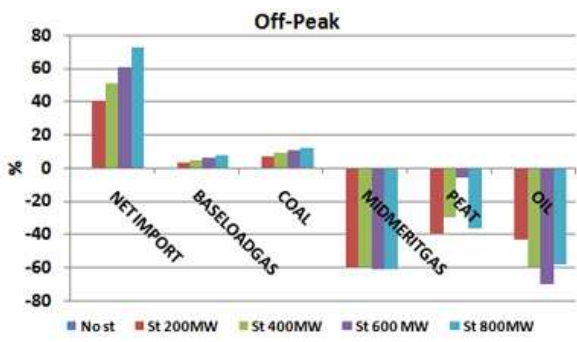

(b) Change in total annual generation with respect to the base-case scenario.

Figure 4: Annual generations of conventional power plants and Irish import and export at off-peak hours.

Figures 4(a) and 4(b) demonstrate the effect of storage capacity on the outputs of conventional power plants and the power flow through the interconnector during the night ${ }^{6}$. It shows that as storage capacity increased, total annual generation of baseload gas and coal plants increased by $2.8 \%-7.4 \%$ and $6.4 \%-11 \%$ respectively. The total net

${ }^{6}$ Night time is defined as the hours between $11.00 \mathrm{PM}$ and $7.00 \mathrm{AM}$ inclusive. 


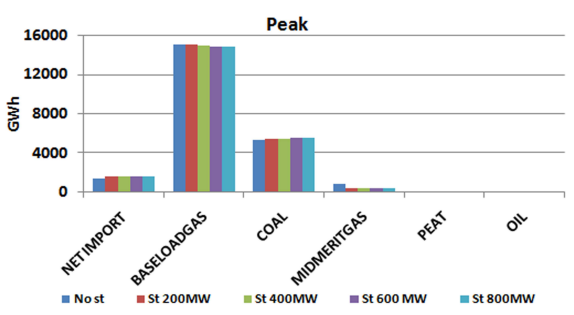

(a) Total annual generation outputs

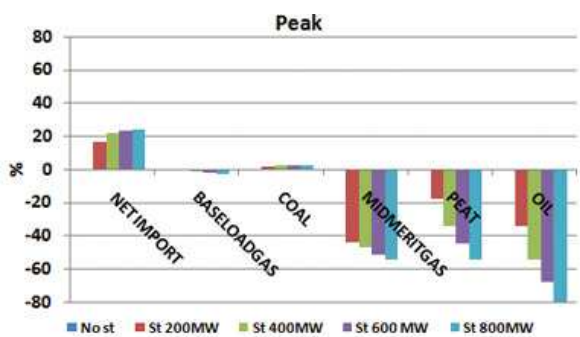

(b) Change in total annual generations with respect to the base-case scenario.

Figure 5: Annual generations of conventional power plants and Irish import and export at peak hours.

import level found to increase by $40 \%-72 \%$ compared to the base-case scenario. These increases in output are used to charge the storage units. During the night, the utilization of midmerit gas plants were found to be decreased by $60 \%$ with the addition of storage over the base-case. This is due to discrete constraints in the unit commitment model. Since the storage unit reduces the demand at the peak hours, these units will not be needed later in the day, so are not switched on at night. In the absence of storage, the start-up time for these units requires them to be kept online over night. Similarly, a significant proportion of the generation of oil plants were found to be displaced. Total generations of peat plants were found to be reduced by approximately $40 \%$ initially as a result of storage deployment and increased as an additional storage capacity (200MW and 400MW) became available.

Figure 5 demonstrates the utilization of conventional units and the interconnector during the day ${ }^{7}$. It shows that the total annual generation of baseload gas and coal plants were affected marginally while the total annual generation of midmerit gas plants fell by $43 \%$ when storage became available. This is due to the reduced net load at peak hours with increasing penetrations of storage. Moreover, when storage capacity was increased up to $800 \mathrm{MW}$, annual generation of midmerit gas plants were reduced by $4 \%$ for every $200 \mathrm{MW}$ increase in storage capacity. A similar effect persisted for the peat and oil fueled plants and their total annual generations were found to have fallen by $17 \%-54 \%$ and 37\%-79\% respectively. Also, the cumulated annual net import level found to have increased by $16 \%-24 \%$. It is due to the fact that the GB fuel cost is cheaper than the Irish fuel cost (Table 1).

Therefore, the effect of storage capacity on power system operation was found to be as expected with few exceptions. It was found to increase the generations of baseload

\footnotetext{
${ }^{7}$ Day time is defined as the hours between $8.00 \mathrm{AM}$ and $10.00 \mathrm{PM}$ inclusive.
} 
gas, coal, peat plants and import levels during the night. Due to the fact that the storage system is able to provide reserves (primary, secondary and replacement), the need for midmerit gas, oil and peat plants online is reduced. Hence, the generation of midmerit gas, oil and peat plants was reduced during the night with the introduction of storage. This is in line with Troy et al. (2010). Also, during the day, generation of coal plant was found to be increased because it was no longer required to hold spare capacity for the replacement reserve which was instead facilitated by storage units. With storage providing reserves and energy, the power system is able to maintain the security of supply.

3.3. Simulation results: The effect of storage on the simulated shadow price of electricity and the production cost

Since the economic dispatch decisions relating to the conventional power plants are affected due to the presence of storage, the corresponding fuel cost of the power system and the electricity price that has been set in the marketplace are likely to be affected. Therefore, it is necessary to study the effect of storage on the total dispatch cost of the power system and the electricity price in order to explore the net cost or the benefit to the system. This approach would show the value of storage from the societal perspective.

\subsubsection{Production cost}

The results given in the previous subsection demonstrated that the generation output of the conventional plants are affected as storage capacity increases. Figure 6 shows the effects that the changes in the output of conventional power plants have on the total costs of the power system. As midmerit gas plants were found to be displaced (Figure 4) when storage was included initially, the load weighted average cost (LWAC) of electricity was found to decrease from approximately $€ 34 / \mathrm{MWh}$ to $€ 33 / \mathrm{MWh}$ at night. However, as storage capacity increases above 200MW, the production cost increases slightly as generations of conventional power plants increase due to the additional nighttime demand from charging the storage units.

But, during the day, i.e. when storage is generating, the LWAC was found to reduce from $€ 38 / \mathrm{MWh}$ to $€ 35 / \mathrm{MWh}$ as storage capacity increased from $0 \mathrm{MW}$ to $800 \mathrm{MW}$.

When night and day electricity generations are combined, the total cost of the power system was found to reduce as the slight increase in the cost at off-peak hour is not higher than the reduction in the cost during peak hours. This is in line with the existing literature (Tuohy and O’Malley, 2011). 


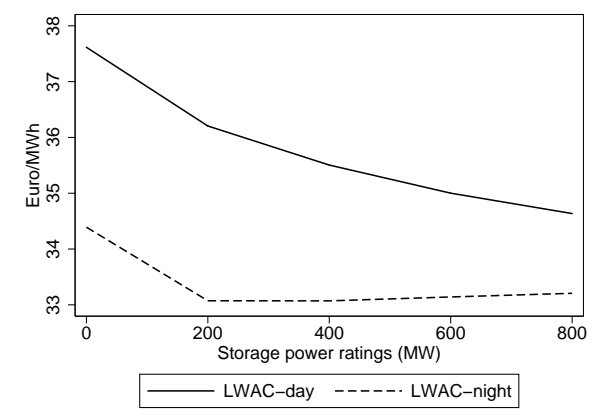

Figure 6: Load Weighed Average Cost per MWh.

\subsubsection{System marginal price}

Given the way in which the WILMAR tool sets the price, the reduction of the electricity cost due to the storage deployment would not necessarily reduce the electricity price. This is because the WILMAR tool allocates the generation schedules for the power plants based on the economic dispatch, and sets the price of electricity equal to the marginal cost of the intraday balance equation (Tuohy et al., 2009a). The marginal cost can be approximated according to how the generation of midmerit gas plants are affected as it is most likely that these plants would be the marginal power plants, i.e. would be dispatched to meet the change in electricity demand.

Therefore, the effect of storage on the wholesale price can be proxied by how storage affects the midmerit gas plants (marginal plants). Table 2 shows the number of hours midmerit gas plants were online throughout the year simulated, and fixed and variable fuel consumptions. Unit 1 has the lowest fixed cost while the Units 2 and 3 are next expensive units. If midmerit gas plants are categorized by their ability to ramp and start up (from hot, warm and cold states) according to Tuohy and O‘Malley (2011), Unit 1 is considered to be flexible while Units 2 and 3 are considered to be relatively inflexible. Since, storage is able to provide more economic reserves and capacity, Unit 3, which has the highest fixed cost, was found to be displaced completely by the storage units. Also, it can be seen that the generation of Unit 1 was displaced as the storage capacity increased. The number of online hours of Unit 2 were found to be increased slightly as Units 1 and 3 were displaced. Therefore the electricity prices are set by Unit 2 more often as storage capacity increases as it would, most likely, be the marginal plant. As shown by variable fuel consumption, once online, Unit 2 is the most expensive of the three units.

Figure 7 shows how storage impacts the load weighed average price (LWAP) as a result of its effect on the dispatch of the marginal plants (midmerit gas plants). When 
Table 2: Online number of hours, fixed fuel consumption and variable fuel consumption of midmerit gas plants.

\begin{tabular}{|r|rrr|}
\hline Storage power ratings & Unit 1 & Unit 2 & Unit 3 \\
\hline 0MW & 2422 & 8376 & 5390 \\
200MW & 2037 & 8412 & 0 \\
400MW & 1710 & 8412 & 0 \\
$600 \mathrm{MW}$ & 1402 & 8412 & 0 \\
$800 \mathrm{MW}$ & 1235 & 8412 & 0 \\
\hline Fariable fuel consumption $(\mathrm{GJ} / \mathrm{MWh})$ & 6.003 & 6.516 & 6.074 \\
\hline
\end{tabular}

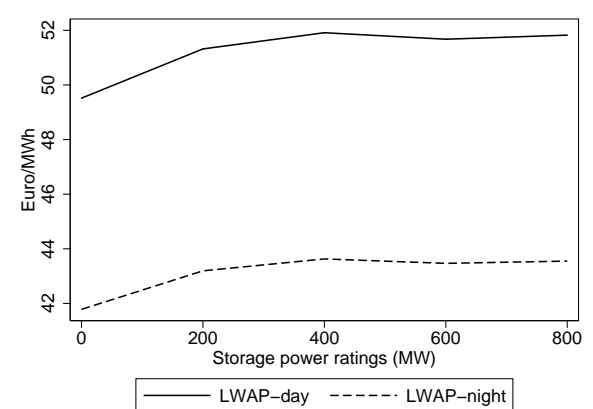

Figure 7: Load Weighed Average Price per MWh.

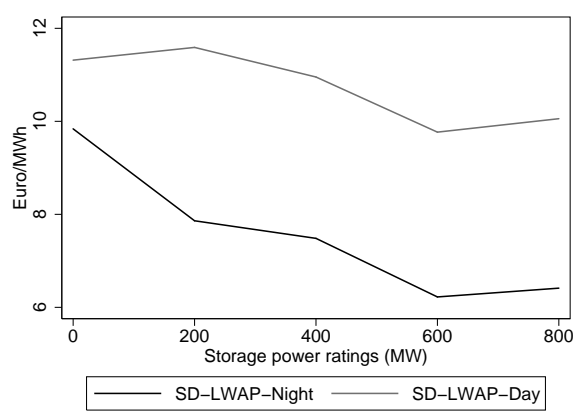

Figure 8: Standard deviation of hourly electricity price.

no storage was considered, LWAP was found to have been approximately $€ 42 / \mathrm{MWh}$ at night and $€ 51 / \mathrm{MWh}$ during the day. As expected, the LWAP was found to increase at night as storage units are added.

As is shown in Table 7, because the number of online hours of the flexible midmerit unit was reduced (Unit 1 and 3) due to the deployment of storage and resulted in the inflexible midmerit gas plant (Unit 2) being the marginal plant more often, higher prices are seen more often. Therefore, as storage capacity increases, electricity price was found to be increasing during the day as opposed to decreasing, according to the expectation.

\subsubsection{The volatility of the system marginal price}

According to how the WILMAR tool sets the electricity price, price volatility depends on whether fuel shifting or marginal plant changes occur more frequently as storage units are deployed. Since the participation of the flexible midmerit gas plant (Unit 1) was found to be reduced significantly, the electricity price is most likely to be set by the more inflexible and more expensive midmerit gas plant (Unit 2). Therefore, the deployment of storage units was found to stabilize the hourly electricity price even though electricity prices are set at higher level. This is shown through the reduction in the standard 
deviation of the electricity price from $€ 10$ to $€ 6$ at night and from $€ 11$ to $€ 10$ during the day (Figure 8).

\subsubsection{Comparison of the savings in the consumer cost and the reduction in the production cost}

In the case study system, the total generation of baseload units was found to be increased while the total generations of peaking and midmerit plants were reduced due to the deployment of electricity storage units. However, the total production cost was found to decrease, while equilibrium electricity price (LWAP) was found to increase due to storage. Therefore, total consumer and production costs are compared. The total consumer cost can be approximated by how much electricity supply companies pay in order to buy electricity from the marketplace since the end-use price is unknown.

$$
\text { ConsumerCost }=\sum_{t=1}^{T} \text { WholesalePrice }_{t} * \text { Demand }_{t}
$$

where WholesalePrice is $_{\text {in }}$ the system marginal price at hour $t$ and $T$ is the total number of hours in a simulation.

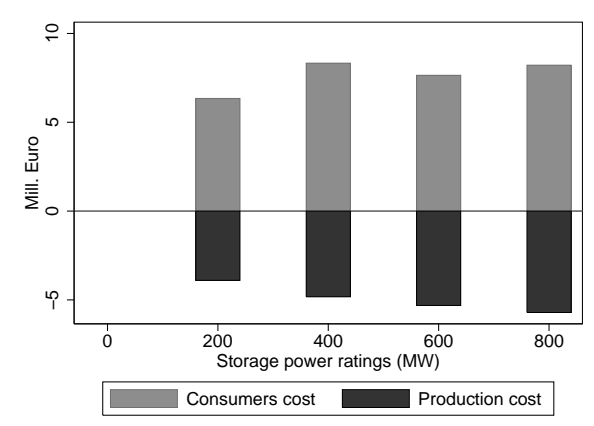

Figure 9: Storage values from the societal and power system perspectives.

Figure 9 shows the changes in production costs and consumers costs approximated by (2) due to storage deployment with respect to the base-case scenario. In terms of the production cost, a reduction of $€ 4$ million was achieved per annum when $200 \mathrm{MW}$ storage became available and this reduction was found to increase by $€ 0.5$ million as the installed storage capacity was increased by $200 \mathrm{MW}$ up to $800 \mathrm{MW}$. The total reduction in the production cost was reached approximately $€ 6$ million per annum at $800 \mathrm{MW}$. The consumer cost, on the other hand, was found to increase by approximately by $€ 6$ million per annum due to the deployment of storage initially. When storage capacity of 400MW was considered, the consumers cost was found to have been increased by a further $€ 2$ 
million while further additions of $200 \mathrm{MW}$ did not affect this significantly ${ }^{8}$.

\subsubsection{Sensitivity analysis}

In previous results it is assumed that the storage units can provide the power system with reserve capacity.

Figure 10 compares storage effects on the LWAC and LWAP when the storage unit provide reserve with when it does not provide the reserve.

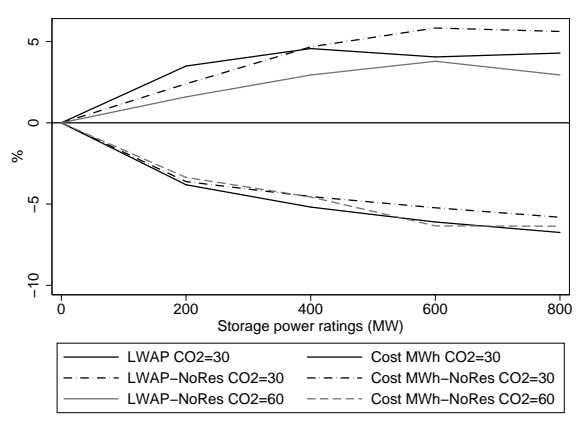

Figure 10: Change in electricity price and production cost of 1MWh of electricity.

When storage was assumed not to provide the reserve, initially its effect on the LWAP was found to be slightly smaller than the effect of the storage that provides reserve. As its installed capacity increases to $600 \mathrm{MW}$ and $800 \mathrm{MW}$, the increase in LWAP was found to be higher than the case with conventional storage. This shows that when the effect of the reserve provided by the storage was excluded, the electricity price is still affected by the deployment of storage. From a fuel cost perspective, reductions in the cost of $1 \mathrm{MWh}$ of electricity were similar for all storage scenarios.

Also a $\mathrm{CO}_{2}$ price of $€ 60 /$ tonne was considered as a sensitivity for the above analysis. The effect of storage on the LWAP for the higher $\mathrm{CO}_{2}$ price scenario was found to be significantly less pronounced than was the case with the lower $\mathrm{CO}_{2}$ price scenario. Moreover, the effect of deploying storage units on the LWAC is also shown to be slightly less pronounced when a higher carbon price was considered.

\subsection{Econometric estimation}

\subsubsection{Data}

Half-hourly ex-post wholesale prices, generation of pumped hydro units, conventional power plants, wind farms and power flows through the inteconnectors in the Irish Single

${ }^{8}$ WILMAR tool calculates the price level by the marginal value of the objective function which is the total cost of the power system. Therefore the dip in the consumers cost, when storage capacity is $600 \mathrm{MW}$, is attributed to the change of price setting plants from Unit 2 to Unit 1 (Table 2). 
Electricity Market (SEM) during 2009 (SEMO, 2011) are used in this paper to identify the effects of pumped hydro storage operations on the actual wholesale electricity price in Ireland.

The existing pumped hydro unit in the SEM consist of 4 units with 73MW of installed capacity each and approximately 4 hours of energy capacity. In the SEM, unit commitment is scheduled every half hour, hence storage operation could change from pump mode to generation mode within an hour. The ex-post hourly electricity price is based on the market scheduling software run that is carried out four days after the delivery date and as such is able to utilize full sets of actual wind and load data with no forecast values (SEMO, 2011).

Since the SEM-O database contains only the system load which is the demand net of the wind output, the half-hourly demand profile is constructed from the generation, import and storage charging profiles:

$$
d_{t}=\sum_{i}^{m} q_{t}^{i}-q_{t}^{s t-p u m p}+q_{t}^{i m}
$$

where $m$ is the total number of power plants, $d_{t}$ is the demand, $q_{t}^{i}$ is the metered generation of power plant $i$ at hour $t, q_{t}^{\text {st-pump }}$ is storage pumping and $q_{t}^{i m}$ is the import from GB.

The daily spot prices ${ }^{9}$ per barrel of oil, and tonne of gas, coal and carbon for 2009 were obtained from various global exchanges which were then converted into euro based on the daily exchange rates for the year.

\begin{tabular}{|c|c|c|c|c|c|}
\hline Variable & Obs & Mean & Std. Dev. & Min & Max \\
\hline WholesalePrice $t(€ / \mathrm{MWh})$ & 12456 & 37.136 & 16.204 & 14.44 & 350.43 \\
\hline $\operatorname{Demand}_{t}(\mathrm{MW})$ & 12456 & 4186.668 & 971.2286 & 2082.409 & 6502.824 \\
\hline$W$ ind $_{t}(\mathrm{MWh})$ & 12456 & 159.7251 & 122.1177 & .224 & 529.085 \\
\hline$P_{\text {coal }}(€ / \mathrm{bbl})$ & 12456 & 36.89039 & 5.120261 & 31.2549 & 51.40111 \\
\hline$P_{\text {gas }}(€ / \mathrm{t})$ & 12372 & 36.79153 & 11.45994 & 25.27127 & 69.61626 \\
\hline$P_{\text {oil }}(€ / \mathrm{t})$ & 12372 & 44.50905 & 6.700267 & 31.79472 & 54.31594 \\
\hline$P_{\text {carbon }}(€ / \mathrm{t})$ & 12372 & 13.33226 & 1.529554 & 8.2 & 15.8 \\
\hline
\end{tabular}

The summary statistics of the data employed is shown in Table 3. Half hourly WholesalePrice $_{t}$ ranged from $€ 14.44-€ 350.43$ while the estimated demand was found to range from $2082 \mathrm{MW}-6502 \mathrm{MW}^{10}$.

${ }^{9}$ Oil price is according to the UK Brent Crude Index $(\$ / \mathrm{bbl})$. Gas price is according to UK National Balancing Point price $(£ / t)$. Coal price is according to the Coal Newcastle Index $(\$ / t)$. Carbon price is according to ECX exchange price $(€ / \mathrm{t})$.

${ }^{10}$ The difference between the demand profile assumed in this section and Section 2 is attributed to the difference between half-hourly and hourly profiles. 
In the SEM, pumped hydro units are utilized daily by the market to balance the electricity demand and electricity supply. Therefore, based on Figure 1, the storage unit is assumed to be interrupted if the total amount of electricity used to pump water or the electricity generated by the storage unit is less than 10MWh during one day. Dummy variables for storage interruptions $D_{t}^{\text {pump }}$ and $D_{t}^{\text {generate }}$ are estimated so that it takes the value of 1 if the storage unit is interrupted over the hours when pumping is most likely to occur (off-peak hours) and generation is most likely to occur (peak hours) respectively, or 0 if the storage unit is uninterrupted. The total number of interruptions are summarized by each storage unit in Table 4 .

Table 4: Number of estimated interruptions ${ }^{1}$ for Turlough Hill storage units in 2009.

\begin{tabular}{c|rrrr} 
& Unit 1 & Unit 2 & Unit 3 & Unit 4 \\
\hline$D_{t}^{\text {pump }}$ & 1195 & 1872 & 631 & 343 \\
$D_{t}^{\text {generation }}$ & 720 & 432 & 180 & 450 \\
\hline${ }^{1}$ Based on the half-hourly storage output profiles.
\end{tabular}

In this study, multiple time series regressions, specified by (1), are estimated to investigate the effect of interruptions in storage operations on the wholesale price. Electricity demand and the availability of wind for generation exhibits seasonality therefore, controls are included for each hour of the day, day of the week and months to control for the unobserved heterogeneity.

\subsubsection{Actual effect of storage on the wholesale price}

Table 5 presents the results of regressions that investigate the effects of interruptions in storage operations while controlling for the main drivers of SMP such as demand, wind and the fuel spot prices of the previous day. While the power plants are required to bid continuously for 24 hours a day and 7 days a week, exchanges are closed over the weekend. Thus, weekend observations are excluded from the regressions. The log of the wholesale price has been used as a dependent variable instead of the actual wholesale price. When autocorrelation and partial autocorrelation functions of the log of the wholesale price are examined, the $A R(2)$ model found is to fit the data well, hence two lags of autoregressive and no moving average parts are included.

Regressions 1-4 in Table 5 explore the impact of interruptions in each storage unit on the $\log$ of the wholesale electricity price of electricity. The demand was found to have a positive effect on the wholesale electricity price as if demand increases a unit with higher fuel cost has to be dispatched in order to meet the demand, causing an increase in price. The effect of an increase in wind output was found to have a significant negative and nonlinear effect on the wholesale electricity price, as it would be displacing 
Table 5: Effect of storage interruptions on the SMP

\begin{tabular}{|c|c|c|c|c|}
\hline VARIABLES & $\begin{array}{r}(1) \\
\text { Unit } 1 \\
\end{array}$ & $\begin{array}{r}(2) \\
\text { Unit } 2 \\
\end{array}$ & $\begin{array}{r}(3) \\
\text { Unit } 3 \\
\end{array}$ & $\begin{array}{r}(4) \\
\text { Unit } 4 \\
\end{array}$ \\
\hline$D_{t}^{\text {generation }}$ & $\begin{array}{r}-0.0201^{* * *} \\
(0.00483)\end{array}$ & $\begin{array}{r}-0.00172 \\
(0.00805)\end{array}$ & $\begin{array}{r}-0.0250^{* * *} \\
(0.00889)\end{array}$ & $\begin{array}{r}-0.0170^{* * *} \\
(0.00508)\end{array}$ \\
\hline$D_{t}^{\text {pumping }}$ & $\begin{array}{r}0.00846^{* * *} \\
(0.00273)\end{array}$ & $\begin{array}{r}-0.0326^{* * *} \\
(0.00328)\end{array}$ & $\begin{array}{c}0.00767^{* *} \\
(0.00340)\end{array}$ & $\begin{array}{r}0.00332 \\
(0.00438)\end{array}$ \\
\hline Demand $_{t}$ & $\begin{array}{r}0.000125^{* * *} \\
(1.84 \mathrm{e}-05)\end{array}$ & $\begin{array}{r}0.000102^{* * *} \\
(1.88 \mathrm{e}-05)\end{array}$ & $\begin{array}{r}0.000128^{* * *} \\
(1.85 \mathrm{e}-05)\end{array}$ & $\begin{array}{r}0.000132^{* * *} \\
(1.83 \mathrm{e}-05)\end{array}$ \\
\hline Wind $t$ & $\begin{array}{r}-6.65 \mathrm{e}-05^{* *} \\
(3.08 \mathrm{e}-05)\end{array}$ & $\begin{array}{r}-8.69 \mathrm{e}-05^{* * *} \\
(3.10 \mathrm{e}-05)\end{array}$ & $\begin{array}{r}-6.19 \mathrm{e}-05^{* *} \\
(3.09 \mathrm{e}-05)\end{array}$ & $\begin{array}{r}-6.40 \mathrm{e}-05^{* *} \\
(3.09 \mathrm{e}-05)\end{array}$ \\
\hline$P_{\text {coal }}$ & $\begin{array}{r}-0.00281^{* * *} \\
(0.00106)\end{array}$ & $\begin{array}{r}-0.00216^{* *} \\
(0.00104)\end{array}$ & $\begin{array}{r}-0.00231^{* *} \\
(0.00105)\end{array}$ & $\begin{array}{r}-0.00282^{* *} \\
(0.00111)\end{array}$ \\
\hline$P_{g a s}$ & $\begin{array}{r}0.00637^{* * *} \\
(0.000706)\end{array}$ & $\begin{array}{r}0.00646^{* * *} \\
(0.000704)\end{array}$ & $\begin{array}{r}0.00637^{* * *} \\
(0.000706)\end{array}$ & $\begin{array}{r}0.00649 * * * \\
(0.000735)\end{array}$ \\
\hline$P_{\text {oil }}$ & $\begin{array}{r}0.00319 * * * \\
(0.000627)\end{array}$ & $\begin{array}{r}0.00361^{* * *} \\
(0.000638)\end{array}$ & $\begin{array}{r}0.00314^{* * *} \\
(0.000625)\end{array}$ & $\begin{array}{r}0.00301^{* * *} \\
(0.000633)\end{array}$ \\
\hline$P_{\text {carbon }}$ & $\begin{array}{r}0.000392 \\
(0.00148)\end{array}$ & $\begin{array}{r}0.000926 \\
(0.00152)\end{array}$ & $\begin{array}{r}-0.000721 \\
(0.00151)\end{array}$ & $\begin{array}{r}-0.00109 \\
(0.00157)\end{array}$ \\
\hline Constant & $\begin{array}{c}0.726 * * * \\
(0.0727)\end{array}$ & $\begin{array}{r}0.744^{* * *} \\
(0.0722)\end{array}$ & $\begin{array}{r}0.703^{* * *} * \\
(0.0722)\end{array}$ & $\begin{array}{r}0.722^{* * *} \\
(0.0745)\end{array}$ \\
\hline Obs & 12372 & 12372 & 12372 & 12372 \\
\hline$R^{2}$ & 0.886 & 0.886 & 0.886 & 0.886 \\
\hline \multicolumn{5}{|l|}{ Auxiliary regression ${ }^{1}$} \\
\hline$e_{t-1}$ & $\begin{array}{r}0.1096 \\
(1.454)\end{array}$ & $\begin{array}{r}0.1051 \\
(1.395)\end{array}$ & $\begin{array}{r}0.1118 \\
(1.483)\end{array}$ & $\begin{array}{r}0.1034 \\
(1.374)\end{array}$ \\
\hline
\end{tabular}

the outputs of several thermal units. The gas and oil prices found to have significant positive effects on the wholesale electricity price; this is most likely due to the fact that $64.3 \%$ of Ireland's installed capacity uses natural gas and oil (IAE, 2011). But the coal price was found to have a negative and significant effect. Carbon price was found to have an insignificant positive effect on the wholesale price of electricity. Coefficients of these control variables were found to be stable across different regressions and in line with O'Mahony and Denny (2011). Considerably high $R^{2}$ with significant explanatory variables implies that the model fits the data and is a good predictor of the wholesale electricity price.

The effects of interruptions in storage generation were found to have significant negative effects on the wholesale electricity price (except Unit 2). This is unexpected based on the theory but in line with results from the unit commitment simulations in previous sections. This is due to the fact that storage units contribute to the flexibility of the power system by providing ancillary services. When its ability to provide ancillary services are reduced, another thermal plant is likely to be dispatched in order to maintain 
the security of the system. Thermal units usually have minimum output levels, and the dispatch of the new thermal unit is likely to reduce the generation of the marginal unit; hence the price set by the marginal plant is affected

When there is an interruption in the pumping of Unit 4, its effect was found to have an insignificant effect on the wholesale electricity price, while an interruption in Unit 2 was found have a negative and significant effect on the wholesale price of electricity. Interruptions in Unit 1 and Unit 3 were found to have significant positive effects.

The robustness of the results presented in Regressions 1-4 of Table 5 are checked in Table 6 . Regression 5 includes dummy variables that take the value of 1 if there is at least one storage unit interrupted, and it is estimated for the storage pumping and generation. Coefficients of these dummy variables show that interruptions in storage pumping and generation have negative and significant effects on the wholesale electricity price.

\begin{tabular}{r|rr}
\multicolumn{2}{c}{ Table 6: Robustness test } \\
$(5)$ & $(6)$ \\
& Interruptions & Number of interrupted units \\
\hline$S t_{t}^{\text {generation }}$ & $-0.0182^{* * *}$ & $-0.0170^{* * *}$ \\
& $(0.00353)$ & $(0.00323)$ \\
$S t_{t}^{\text {pump }}$ & $-0.0170^{* * *}$ & $-0 . .0141^{* * *}$ \\
& $(0.00311)$ & $(0.00258)$ \\
\hline Obs & 12372 & 12372 \\
$R^{2}$ & 0.886 & 0.886 \\
\hline Auxiliary regression & 0.1163 & 0.1181 \\
$e_{t-1}$ & $(1.54)$ & $(1.57)$ \\
\hline \multicolumn{2}{c}{ Robust standard errors in parentheses } \\
$* * * \mathrm{p}<0.01,{ }^{* *} \mathrm{p}<0.05,{ }^{*} \mathrm{p}<0.1$
\end{tabular}

Since the existing Turlough Hill pumped hydro units are identical, the dispatch of a single unit may not have a major impact on the power system, as long as the total output level of the storage system is not impacted. When one of the four units is interrupted, the remaining storage capacity would be able to cope with the system requirements. When more than one unit is interrupted, the capacity remaining may not be able to provide the same service as the full storage capacity would provide. Therefore, the number of interrupted units at the same time has been included in the regression instead of the dummy variable for the interruption in a single unit (Regression 6). It was found that 2 units at most were interrupted at the same time for both storage pumping and generation. The number of interrupted units for storage pump mode has been found to have a significant negative effect on the wholesale electricity price. For generation, the number of interrupted units has been also found to have a significant negative effect on the wholesale electricity price. This supports the effect of storage generation on the log 
of wholesale electricity price which was found in Table 5.

Based on the auxiliary regression with robust standard errors, serial correlation was not found to be present in Regressions 1-6. Since resulting test statistics are asymptotically appropriate, whether or not the errors have a constant variance, the regression results are considered to be accurate.

\section{Discussion}

In the Irish system, the actual price paid by electricity suppliers consists of two elements. The marginal price (as represented by the wholesale price in previous sections) and also an 'uplift' payment. This uplift payment compensates generator for start up costs. Table 2 shows the total number of online hours of the midmerit plants and, as storage capacity increases, the number of online hours of midmerit plants were found to have been reduced significantly. Thus, if associated startup/shutdown costs are reduced, the uplift payment should be reduced and the net price should be reduced as a result. Therefore, the increase in the marginal price of electricity (Figure 10) due to storage operation may be offset by the reduction in uplift payments and fuel cost savings. However, this is beyond the scope of this paper. Also, as was shown in Figure 8, the supply company's risk of buying electricity from the marketplace at high prices at peak hours is reduced; hence supply companies may reduce retail prices to consumers.

If the storage system is optimised in an attempt to displace the baseload power plants by the renewable energy generations, the total cost of the power system will reduce significantly. However, the equilibrium electricity price would not be affected as the price setting plants on the top of the merit order remain untouched.

When a high carbon cost scenario was considered, the effect of storage on the electricity price became less pronounced. In the scenario with even higher carbon prices, less efficient power plants would become uneconomic based on their carbon costs and would be displaced by renewable generation or more efficient plants with low operational costs. In such cases, the deployment of storage units would benefit the system by utilizing efficient units more and displacing the remaining inefficient high-cost plants at peak hours. This would achieve considerable fuel savings as well as potential price reductions.

To integrate the renewable energy into the generation mix securely, it is estimated that the Irish power system need to have the back-up capacity of approximately $80-95 \%$ (Meray, 2011). Currently, the Irish electricity market rules requires the power system to carry $81 \%$ of the largest infeed online as a primary reserve and a secondary reserve (Eirgrid Transmission System Operator, 2010) to deal with the sudden reduction in generating capacity or increase in electricity demand. In the future, requirements for 
the reserve and back-up capacity are expected to increase in the Irish electricity market and therefore, the back-up capacity for the non-dispatchable electricity sources would be more valuable than its energy supply (Poyry, 2011).

In terms of the effect of utilizing storage units to store excess electricity, econometric estimations presented in Table 5 do not fully support simulation results presented in Figure 7 fully. This could be attributed to the fact that the power plant characteristics may not be exactly the same in the WILMAR tool and in the SEM.

It should be noted that the results discussed in this paper are the Irish case specific. Therefore, it differs from the theoretical effect of storage on the equilibrium electricity price, which is shown in Crampes and Moreaux (2010). Also, it does not reflect the market exactly when it is setting the electricity price. However, it provides a good proxy for the benefits of storage.

In future work, differentiated incremental heat rate slopes, which should be increasing with the level of outputs, should be considered in order to reflect better price and quantity pairs used in the SEM.

\section{Conclusion}

This paper investigated the impact of deploying storage units on the electricity price through its effect on the power system operations. It was found that the utilization of the storage system increases the generation of baseload plants and the net import level at off-peak hours, and displaces the generation of oil and midmerit gas plants at peak hours. Hence, a considerable reduction in production costs was achieved.

However, the simulated electricity price was found to increase as a result of deploying storage units because of its effect on the marginal plants. It was found that the savings in the fuel cost achieved was not able to justify the increased cost of electricity to consumers. In the real world, storage generation was found to result in a higher wholesale electricity price. This partially supports the simulation results.

If all indirect storage effects (such as the effect on the uplift payment and reduction in price volatility) are considered, the increased consumer costs may be justified. Finally, at a high carbon price scenario, the effect of storage on the electricity price was found to be less pronounced.

\section{References}

Abbey, C., Joós, G., 2007. Supercapacitor energy storage for wind energy applications. IEEE Transaction on industry applications $43(3)$.

Ahlert, K.-H., Block, C., 2010. Assessing the impact of price forecast errors on the economics of distributed storage systems. Proc. 43rd Hawaii Int. Conference on System Science. 
AIGS, January 2008. All Island Grid Study. Tech. rep., Department of Enterprise, Trade and Investment and Department of Communications, Energy and Natural Sources of Ireland.

Benitez, L. E., Benitez, P. C., van Kooten, G. C., 2008. The economics of wind power with energy storage. Energy Economics 40, 1973-1989.

Brown, P., Lopes, J. A. P., 2008. Optimization of pumped storage capacity in an isolated power system with large renewable penetration. IEEE Transactions on Power systems 23 (2).

Carton, J., Olabi, A., 2010. Wind/hydrogen hybrid systems: Opportunity for irelands wind resource to provide consistent sustainable energy supply. Energy 35, 4536-4544.

Castronuovo, E. D., Lopes, J. A. P., December 2004. Optimal operation and hydro storage sizing of a wind-hydro power plant. International journal of electrical power and energy systems 26 (10), 771-778

CER, 2008. Trade and settlement code version 4.1. Tech. rep., Utility Regulator and Commission for Energy Regulation.

Crampes, C., Moreaux, M., 2010. Pumped storage and cost saving. Energy economics 32, $325-333$.

Dany, G., 2001. Power reserve in interconnected systems with high wind power production. In: in Proc. IEEE Power Tech Conference. Vol. 4. p. 6pp.

Denny, E., O’Malley, M., May 2007. Quantifying the total net benefits of grid integrated wind. IEEE Transactions on Power Systems $22(2)$.

Doherty, R., Outred, H., O’Malley, M., 2005. Generation portfolio analysis for a carbon constrained and uncertain future. International Conference on Future Power Systems.

EirGrid, 2009a. EirGrid monthly availability report - April 2009. Tech. rep.

EirGrid, 2009b. EirGrid monthly availability report - January 2009. Tech. rep.

EirGrid, 2009c. EirGrid monthly availability report - July 2009. Tech. rep.

EirGrid, 2009d. EirGrid monthly availability report - October 2009. Tech. rep.

Eirgrid Transmission System Operator, 2010. Operating Reserve Requirements.

EPRI, 2004. EPRI-DOE Handbook Supplement of Energy Storage for Grid Connected Wind Generation Applications. Tech. Rep. 1008703, CA, and the U.S. Department of Energy, Washington, DC.

EPRI, Palo Alto, 2003. EPRI-DOE Handbook of Energy Storage for Transmission and Distribution Applications. Tech. Rep. 1001834, CA, and the U.S. Department of Energy, Washington, DC.

European Commission, 2006. Action Plan for Energy Efficiency: Realising the Potential (COM(2006)545 final).

European Commission, 2007. Limiting Global Climate Change to 2 degrees Celsius: The way ahead for 2020 and beyond (COM(2007)2).

European Wind Integration Study, 2010. URL www.wind-integration.eu

Friedman, L. S., 2009. The importance of marginal cost electricity pricing to the success of greenhouse gas reduction programs. In: The Annual Research Conference of the Association for Public Policy Analysis and Management, Washington, DC, USA.

Greenblatt, J. B., Succar, S., Denkenberger, D. C., Williams, R. H., Socolow, R. H., March 2007. Baseload wind energy: modeling the competition between gas turbines and compressed air energy storage for supplemental generation. Energy Policy 35 (3), 1474-1492.

IAE, 2011. Energy policy and economic recovery 2010 - 2015. Tech. rep., The Irish Academy of Engineering.

Kaldellis, J. K., Zafirakis, D., Kaldelli, E. L., Kavadias, K., 2009. Cost benefit analysis of a photovoltiacenergy storage electrification solution. Renewable energy 34, 1299-1311.

Korpaas, M., Hildrum, R., Holen, A. T., 2003a. Optimal operation of hydrogen storage for energy sources with stochastic input. In: IEEE Bologna PowerTech conference.

Korpaas, M., Hone, A. T., Hildrum, R., 2003b. Operation and sizing of energy storage for wind power plants in a market system. Electrical power and energy systems 25, 599-606.

Leou, R.-C., 2008. An economic analysis model for the energy storage systems in a deregulated market. In: IEEE International Conference on Sustainable Energy Technologies. pp. 744-749.

Li, W., Joós, G., 2007. Comparison of energy storage system technologies and configurations in a wind farm. In: Power Electronics Specialists Conference. pp. 1280-1285.

Lund, H., Salgi, G., Elmegaard, B., Anderson, A. N., 2009. Optimal operation strategies of compressed air energy storage on eletricity spot markets with fluctuating prices. Applied thermal engineering 29, 799-806.

McDowall, J., 2006. In tegrating energy storage with wind power in weak electricity grids. Journal of Power sources 162, 959-964.

Meray, N., 2011. Wind and Gas. Back-up or Back-out, "That is the Question". Clingendael International Energy Programme. 
National Laboratory for Sustainable Energy, 2010. Wind Power Integration in Liberalised Electricity Market (WILMAR) project.

URL www.wilmar.rosoe.dk

Nieuwenhout, F., Dogger, J., Kamphuis, R., 2005. Electricity storage for distributed generation in the built environment. In: 2005 International Conference on Future Power Systems. pp. 5-10.

Nyamdash, B., Denny, E., 2010. The viability of combining large scale electricity storage with wind generation. Energy policy 38, 7200-7208.

O'Mahony, A., Denny, E., 2011. Electricity prices and generators behaviour in gross pool of electricity markets. fourthcoming.

Poyry, 2011. The challenges of intermittency in North West European power markets.

SEMO, 2011.

URL http://www.sem-o.com/

Sioshansi, R., 2010. Welfare impacts of electricity storage and the implications of ownership structure. The Energy Journal 31 (2), 189-214.

Sioshansi, R., 2011. Increasing the value wind with energy storage. Energy 32 (2), 1-29.

Sioshansi, R., Denholm, P., Jenkin, T., Weiss, J., 2009. Estimating the value of electricity storage in PJM: Arbitrage and somewelfare effects. Energy Economics 31 (269-277).

Susan, S. M., Hassenzahl, W. V., 2003. Long- vs. short-term energy storage technologies snalysis: A lifecycle cost study: A study for the doe energy storage systems program. Tech. rep., Sandia National Laboratories.

Taljan, G., Fowler, M., Cañizares, C., Verbič, G., 2008. Hydrogen storage for mixed wind-nuclear power plants in the context of a hydrogen economy. Hydrogen energy (4463-4475).

Troy, N., Denny, E., O'Malley, M., May 2010. Base-load cycling on a system with significant high wind penetration. IEEE Transactions on Power Systems 25 (2).

Tuohy, A., Denny, E., Meibom, P., O‘Malley, M., May 2009a. Benefits of stochastic scheduling for power systems with significant installed wind power. IEEE Transactions on Power Systems.

Tuohy, A., Meibom, P., Denny, E., O‘Malley, M., 2009b. Unit commitment for systems with significant wind penetration. IEEE Transaction on Power Systems 24 (2), 592-601.

Tuohy, A., O'Malley, M., 2011. Pumped storage in systems with very high wind penetration. Energy policy 39, 1965-1974.

Walawalkar, R., Apt, J., Mancini, R., 2007. Economics of electric energy for energy arbitrage and regulation in New York. Energy Policy, 2558-2568.

Weis, T. M., Ilinc, A., 2008. The utility of energy storage to improve the economcis of wind-diesel power plants in canada. Renewable energy 33, 1544-1557.

Weissensteiner, L., Haas, R., Auer, H., 2011. Offshore wind power grid connection - the impact of shallow versus super-shallow charging on cost-effectectiveness of public support. Energy Policy (39), 4637-4643.

Zafirakis, D., Kaldellis, J. K., 2009. Economic evaluation of the dual mode caes solution for increased wind energy contribution in autonomous island networks. Energy policy 37 (5), 1958-1969.

Zeng, J., Zhang, B., Mao, C., Wang, Y., 2006. Use of battery energy storage systems to improve the power quality and stability of wind farms. In: Internation conference on Power system technologies. 